\title{
O CURSO DE DESENVOLVIMENTO DE HABILIDADES EM PESQUISA DO IBGE
}

\author{
Rita de Cassia Villas Boas e Denise Britz do N. Silva \\ Coordenação de Treinamento e Aperfeiçoamento \\ Escola Nacional de Ciências Estatísticas - ENCEl \\ Instituto Brasileiro de Geografia e Estatística - IBGE, Brasil \\ denise.silva@ibge.gov.br
}

\begin{abstract}
O Instituto Brasileiro de Geografia e Estatística - IBGE possui um Programa de Capacitação para seu corpo técnico no qual o Curso de Desenvolvimento de Habilidades em Pesquisa-CDHP fornece aos participantes uma visão abrangente do processo de planejamento e execução de uma pesquisa domiciliar por amostragem. Partindo de uma demanda especifica apresentada por um cliente, os alunos desenvolvem e executam a pesquisa em condições reais, inclusive com trabalho de campo, e apresentam seus resultados. O curso tem duração de seis semanas em tempo integral e os seus instrutores são especialistas das diversas áreas do IBGE. A primeira edição do CDHP foi realizada em 1998, e até 2014, já foram realizadas 28 edições do curso, demonstrando o sucesso deste projeto de capacitação e confirmando sua importância para a formação de especialistas nas áreas de produção e análise de estatísticas públicas.
\end{abstract}

\section{INTRODUÇÃO}

Grandes empresas identificam o seu corpo de funcionários como sendo o seu maior patrimônio. Na moderna visão gerencial, voltada para melhoria de qualidade no atendimento à sociedade, o desenvolvimento contínuo dos recursos humanos torna-se tarefa primordial. Cabe ao IBGE, na qualidade de Agência Nacional responsável pela produção e coordenação das informações Estatísticas e Geográficas, desenvolver e implementar mecanismos para viabilizar ao seus funcionários o desenvolvimento de competências e o acesso ao conhecimento e utilização de novas metodologias e tecnologias, em consonância com sua missão institucional.

Com relação à política de capacitação e aperfeiçoamneto, o IBGE possui um programa de treinamento visando à capacitação do seu corpo técnico e administrativo. Tal programa é revisto, avaliado e reeditado anualmente. A estruturação e implementação do Programa Anual de Treinamento fica a cargo da Escola Nacional de Ciências Estatísticas (ENCE) que, além de oferecer cursos de Graduação em Estatística, de Pós-Graduação Lato Sensu em Análise Ambiental e Gestão do Território, de Pós-Graduação Strito Sensu (mestrado e doutorado) em População, Território e Estatísticas Públicas, é também responsável pelo treinamento e capacitação dos funcionários do IBGE e servidores públicos de outras instituições.

Uma das principais atividades do IBGE é a de realizar pesquisas cujo planejamento e realização envolvem profissionais de várias áreas de conhecimento sendo de suma importância que os técnicos envolvidos no planejamento, coleta, apuração, análise e divulgação dos resultados das pesquisas tenham conhecimentos básicos e linguagem comuns.

Sendo assim, desde 1997, a ENCE implantou o Curso de Desenvolvimento de Habilidades em Pesquisa (CDHP) para atender a essa demanda de capacitação, visando o aprimoramento do seu corpo técnico e fornecendo aos participantes uma visão abrangente de todo o processo de planejamento e realização de uma pesquisa domiciliar por amostragem probabilística. O curso segue os moldes do Survey Skills Development Course (SSDC) do Statistics Canada (com suas devidas, e imprescindíveis, adaptações ao contexto do IBGE) que, por sua vez, já ultrapassou a $100^{\mathrm{a}}$. edição e é considerado um dos mais importantes na agenda de treinamento daquela instituição.

A concepção e implementação da $1^{\mathrm{a}}$. edição do curso contou com a colaboração da equipe do Survey Skills Development Course. Primeiramente, a ENCE enviou dois professores para participarem do SSDC no Statistics Canada (em maio de 1996), como forma de absorver a metodologia Canadense e habilitá-los para coordenar a implantação do curso no Brasil. Logo após o retorno dos professores ao Brasil, a ENCE recebeu a visita de um dos instrutores do SSDC, responsável por assessorar instituições interessadas em implementar essa proposta de curso. Na ocasião de sua visita, a ENCE recebeu cópia de todo o material didático do curso e foram

In: M.A. Sorto (Ed.), Advances in statistics education: developments, experiences and assessments. Proceedings of the Satellite conference of the International Association for Statistical Education (IASE), July 2015, Rio de Janeiro, Brazil. 
discutidas as alterações que seriam necessárias para adaptar o material, e o curso como um todo, às necessidades do IBGE. A primeira edição do curso aconteceu em agosto de 1997.

O CDHP apresenta os principais conceitos, métodos e etapas relevantes para o planejamento e execução de uma pesquisa por amostragem bem como permite que o participante conheça as inter-relações inerentes às diversas atividades desenvolvidas pelo IBGE. Além de oferecer aulas expositivas sobre noções de amostragem, elaboração de questionários e plano tabular, planejamento de operações de campo e sistemas de apuração/expansão para pesquisas por amostragem, o curso propicia a experiência de aprender fazendo, na qual o participante atua ativamente no planejamento e execução da pesquisa sobre um tema previamente escolhido, sob condições reais.

O produto final do curso, o resultado da pesquisa e sua metodologia, são descritos num relatório da pesquisa e são apresentados pelos alunos na cerimômia de formatura do curso. A carga horária do curso é de 6 (seis) semanas em tempo integral, totalizando 240 (duzentos e quarenta) horas, incluindo a atividade de coleta de dados ( 7 a 10 dias de trabalho de campo). A cada realização do curso são treinados 25 técnicos das diversas áreas do IBGE e há vagas para o público externo.

\section{DESCRIÇÃO DO CURSO E SUA DINÂMICA}

O curso visa oferecer aos participantes a experiência de planejar e desenvolver pesquisas domiciliares por amostragem probabilística, apresentando conceitos, métodos e etapas relevantes para o planejamento e execução de uma pesquisa. A dinâmica do curso permite a difusão novas metodologias/tecnologias na insituição, promove a integração do corpo técnico, motivando o trabalho em equipe e forma uma rede de contatos para desenvolvimento de projetos futuros, além de fomentar experiências de parcerias entre o IBGE e entidades que solicitam a pesquisa-tema.

O quadro de instrutores do curso é formado por servidores das diversas áreas do IBGE e o público-alvo do CDHP é composto por servidores do IBGE com formação em nível superior. Além de principalmente atender a demanda interna de capacitação, a participação no curso também está aberta a alunos de pós-graduação (mestrado e doutorado), particularmente das áreas de Ciências Sociais e Estatística de instituições de ensino públicas brasileiras, servidores de órgãos públicos envolvidos no planejamento e execução de pesquisas quantitativas no Brasil e nos Países Africanos de Língua Oficial Portuguesa, docentes e pesquisadores de institutos de pesquisas e de instituições de ensino públicas brasileiras e servidores de agências e organizações públicas do país.

O conteúdo programático do CDHP abrange as competências necessárias para a realização de pesquisas domiciliares amostrais. O curso é composto por aulas expositivas sobre introdução à metodologia de pesquisas quantitativas, noções de amostragem, elaboração de questionários e plano tabular, planejamento da operação de campo e desenvolvimento de sistemas de apuração/expansão para pesquisas por amostragem. O CDHP contempla também seminários, dinâmicas de grupo e diversas outras atividades que são executadas em laboratórios para os quais a turma é dividida em cinco grupos. Cada grupo fica responsável por um dos pilares da pesquisa, a saber: tema, questionário, amostragem, sistemas e (trabalho de) campo. Os grupos, compostos por 5 alunos cada um, trabalham sob a coordenação de instrutores para desenvolver os diversos componentes da pesquisa.

É importante ressaltar que os instrutores do CDHP atuam nos laboratórios como consultores mas não fazem a pesquisa, que é planejada e realizada pelos participantes do curso. Os grupos interagem em suas tarefas diárias e participam de duas reuniões com o cliente da pesquisa para discutir os objetivos da pesquisa e, posteriormente, apresentar o projeto de pesquisa (mais especificamento o plano tabular e o questionário).

Dentre as atividades práticas realizadas pelos participantes do curso, destacam-se: encontros com o cliente para definição dos objetivos da pesquisa, elaboração do cronograma e planilha de custos da pesquisa, desenvolvimento do plano tabular para apresentação dos resultados, elaboração do questionário e outros instrumentos de coleta, desenvolvimento do plano amostral da pesquisa e seleção da amostra, especificação dos procedimentos de coleta e apuração, desenvolvimento dos sistemas necessários para entrada de dados, crítica, imputação e tabulação dos resultados, especificação e execução de procedimentos para ponderação da amostra, tratamento 
de não-resposta, cálculo das estimativas e das medidas de precisão, implementação do trabalho de campo, incluindo operação de listagem de domicílios e entrevistas nos domicílios selecionados, e elaboração do relatório final contendo a metodologia utilizada e uma síntese dos resultados da pesquisa.

\section{O CLIENTE DA PESQUISA}

A primeira etapa do planejamento do curso refere-se à escolha do tema da pesquisa e, consequentemente, do seu cliente. Os temas devem ser de relevância para a sociedade e podem abordar aspectos não pesquisados habitualmente pelo IBGE. Nesse sentido, ratifica-se o papel do CDHP como laboratório experimental de inovações não apenas metodológicas e tecnológicas, mas também temáticas, contribuindo para o contínuo exercício da missão institucional do IBGE.

Para ser cliente do CDHP, a entidade proponente da pesquisa deve ser (ou estar inserida em) uma instituição pública sem fins lucrativos, cujo projeto de pesquisa vise à melhoria de algum serviço prestado à sociedade ou à obtenção de conhecimento ou informação que enriqueça o debate sobre questões de interesse público. Caso a instituição se localize fora do município do Rio de Janeiro, deve ficar responsável pelo financiamento do trabalho de campo, cobrindo os custos relativos ao deslocamento, acomodação e diárias para os alunos e os instrutores que os acompanham, e do apoio logístico para o trabalho de campo, ou seja, transporte para as entrevistas, telefones para a comunicação entre a base de coleta e a área de coleta, e etc.

Diversas entidades da esfera pública, tais como prefeituras municipais, secretarias de estado, universidades, órgãos públicos federais, além do próprio IBGE, foram os clientes das pesquisas nas edições já realizadas do curso. As propostas de temas de pesquisa são avaliadas pelas instâncias adequadas quanto à sua viabilidade e oportunidade para implementação numa das edições do CDHP, considerando-se as restrições metodológicas e operacionais do curso. Ao iniciar o planejamento de cada edição do CDHP, o cliente responsáveil pela proposta aprovada é consultado sobre a disponibilidade para trabalhar com a equipe do CDHP na implementação da pesquisa. A avaliação da proposta leva em conta: a adequação do tema a uma pesquisa domiciliar que possa ser implementada numa edição do CDHP, a oportunidade, relevância e o ineditismo do tema da pesquisa solicitada (tanto no CDHP como no IBGE), as características e o comprometimento do cliente com a realização da pesquisa sobre o tema proposto, e o potencial de aproveitamento dos resultados da pesquisa pela sociedade. As propostas de temas são encaminhadas à Coordenação do CDHP contendo: justificativa e discussão da relevância e oportunidade da pesquisa sobre o tema proposto, descrição e contextualização do tema, principais variáveis de investigação e identificação da população alvo da pesquisa. Até o momento, foram realizadas vinte e oito edições do CDHP, cujos temas de pesquisa e respectivos clientes são listados a seguir:

1. Hábitos e Opiniões dos Moradores do Bairro de Irajá - Prefeitura do Rio de Janeiro, IPLANRIO, 1997.

2. Saúde e Meio Ambiente nos Bairros de Taquara e Curicica - IBGE, Diretoria de Geociências, 1998.

3. Hábitos Culturais e de Lazer dos Moradores das Adjacências do Museu da República IPHAN, Ministério da Cultura, Museu da República, 1998.

4. Resolução de Conflitos Domésticos e Violência Intrafamiliar nos Bairros da Tijuca e do Maracanã - Secretaria de Segurança Pública do Estado do Rio de Janeiro, Subsecretaria de Pesquisa e Cidadania, 1999.

5. Características da População Urbana de Macaé - Prefeitura de Macaé, Secretaria Municipal de Planejamento e Coordenação Geral, 1999.

6. Percepção dos Moradores da Ilha do Governador sobre o Programa de Despoluição da Baía de Guanabara - Universidade Federal do Rio de Janeiro, Instituto de Filosofia e Ciências Sociais, Departamento de Ciência Política, 2000.

7. Uso do Tempo - IBGE, Diretoria de Pesquisas, 2001.

8. Uso Social, Percepção da Violência e Vitimização nos Bairros de Copacabana e Leme IBGE, ENCE, Coordenação da Pós-graduação, 2001.

9. Conhecimento do Museu da Vida - Museu da Vida, Fundação Oswaldo Cruz, 2002. 
10. Região Portuária: Perfil, Demandas e Expectativas dos Moradores - Prefeitura do Rio de Janeiro, Instituto Pereira Passos, 2002.

11. Características, Percepções e Demandas da População Residente no entorno da ENCE IBGE, ENCE, Coordenação de Graduação, 2003.

12. Pesquisa sobre Tecnologias de Informação e Comunicação - IBGE, Diretoria de Pesquisas, 2003.

13. Segurança Alimentar Domiciliar - IBGE, ENCE, Coordenação da Pós-graduação, 2004.

14. Pesquisa sobre Reciclagem e Coleta de lixo - IBGE, ENCE, Coordenação da Pós-graduação, 2004.

15. Pesquisa sobre Arranjos Domiciliares - IBGE, ENCE, Coordenação da Pós-graduação, 2004.

16. Qualidade de Vida dos Moradores de 60 Anos ou Mais de Idade do Bairro de Copacabana IBGE, Diretoria de Pesquisas, 2005.

17. Pesquisa sobre a Participação Ativa da Melhor Idade - IBGE, Diretoria de Pesquisas, 2005.

18. Pesquisa Domiciliar sobre Necessidades Habitacionais em Campos dos Goytacazes - UENF, 2006.

19. Pesquisa sobre a Revitalização do Bairro de São Cristóvão e entorno da Rua Ceará - Prefeitura do Rio de Janeiro, Instituto Pereira Passos, 2006.

20. Pesquisa sobre Cães e Gatos - Humanização e Padrões de Consumo - UFRRJ, 2007.

21. Pesquisa sobre Atitudes e Hábitos de Consumo Sustentável - IBGE, Diretoria de Pesquisas, 2008.

22. Pesquisa sobre Percepção e Visita a Museus - Fundação Oswaldo Cruz, Observatório de Museus e Centros Culturais (OMCC), 2008.

23. Pesquisa sobre o Sentimento de Insegurança - Diretoria de Pesquisas, 2009.

24. Pesquisa sobre Hábitos Culturais e de Lazer dos Moradores do Entorno da Fundação Casa de Rui Barbosa - Fundação Casa de Rui Barbosa, 2011.

25. Pesquisa sobre Deslocamentos Populacionais - IBGE, Diretoria de Pesquisas, 2011.

26. Pesquisa sobre Informações de Serviços de Saúde a partir de TIC - Núcleo de Informação e Coordenação do Ponto BR, NIC.BR, 2012.

27. Pesquisa da Frota de Veículos Leves nos Bairros do Méier e Todos os Santos - Empresa de Pesquisa Energética - EPE, 2013.

28. Pesquisa sobre a Transferência do Transporte Individual para o Transporte Coletivo Empresa de Pesquisa Energética - EPE - 2014

\section{CONSIDERAÇÕES FINAIS}

O sucesso do CDHP foi consolidado ao longo dos anos. Informações sobre novas edições do curso estão disponíveis em (http://www.ence.ibge.gov.br/index.php/portal-cdhp). O curso capacita novos funcionários em competências necessárias para o trabalho do IBGE e desenvolve um compromisso com a missão institucional, bem como permite que aqueles já experientes na instituição possam vivenciar o processo de pesquisa, estimulando a reflexão sobre as práticas utilizadas, a importância do trabalho em equipe e da integração intergeracional na instituição. Vários participantes do curso, após a experiência do CDHP, decidiram continuar sua formação realizando estudos de pós-graduação.

O CDHP é sem dúvida um carro-chefe do programa de treinamento do IBGE e atrai também participantes externos que buscam capacitação na área de pesquisas e levantamentos estatísticos, dado seu ineditismo no país, sua especificidade e a marca de qualidade do IBGE no que se refere à excelência na realização de pesquisas. Não há no Brasil curso similiar ao CDHP que ofereça ao seus participantes a combinação exitosa de teoria e prática na área de métodos para pesquisas quantitativas. Em suas 28 edições, o curso já capacitou mais de 650 pessoas, tendo um papel vital na formação de quadros para o IBGE permitindo a capacitação de seus funcionários, em especial aqueles recém-concursados, em competências diretamente associadas ao saber e à missão da instituição. 


\section{REFERÊNCIAS}

Gambino, J. \& Gough, H. (2005, August). Teaching sampling in a government statistical agency: the Canadian experience. Proceedings of the $55^{\text {th }}$ Session of the International Statistical Institute, Sydney, NSW, Australia, 55.

Provost, M. (2001, August). Training in the context of a national statistical agency: the survey skills development course perspective. Proceedings of the Annual Meeting of the American Statistical Association, Atlanta, Georgia, USA, 24.

Storino, G. (2000, setembro). O conceito de learning organization aplicado a administração pública brasileira. Anais do Encontro Anual da Associação Nacional dos Programas de PósGraduação e Pesquisa em Administração, Florianópolis, SC, Brasil, 24. 